\title{
SPS-neutralization in tissue samples for efficacy testing of antimicrobial peptides
}

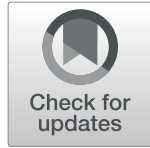

\author{
Gabrielle Sherella Dijksteel ${ }^{1,2^{*}}$ (D) Peter H. Nibbering ${ }^{3}$, Magda M. W. Ulrich ${ }^{1,2}$, Esther Middelkoop ${ }^{1,2}$ \\ and Bouke K. H. L. Boekema ${ }^{1}$
}

\begin{abstract}
Background: Accurate determination of the efficacy of antimicrobial agents requires neutralization of residual antimicrobial activity in the samples before microbiological assessment of the number of surviving bacteria. Sodium polyanethol sulfonate (SPS) is a known neutralizer for the antimicrobial activity of aminoglycosides and polymyxins. In this study, we evaluated the ability of SPS to neutralize residual antimicrobial activity of antimicrobial peptides [SAAP-148 and pexiganan; 1\% (wt/v) in PBS], antibiotics [mupirocin (Bactroban) and fusidic acid (Fucidin) in ointments; $2 \%(\mathrm{wt} / \mathrm{wt})$ )] and disinfectants [2\% (wt/wt) silver sulfadiazine cream (SSD) and 0.5\% (v/v) chlorhexidine in 70\% alcohol].

Methods: Homogenates of human skin models that had been exposed to various antimicrobial agents for $1 \mathrm{~h}$ were pipetted on top of Methicillin-resistant Staphylococcus aureus (MRSA) on agar plates to determine whether the antimicrobial agents display residual activity.

To determine the optimal concentration of SPS for neutralization, antimicrobial agents were mixed with PBS or increasing doses of SPS in PBS (0.05-1\% wt/v) and then $10^{5}$ colony forming units (CFU)/mL MRSA were added. After 30 min incubation, the number of viable bacteria was assessed. Next, the in vitro efficacy of SAAP-148 against various gram-positive and gram-negative bacteria was determined using PBS or $0.05 \%$ (wt/v) SPS immediately after 30 min incubation of the mixture. Additionally, ex vivo excision wound models were inoculated with $10^{5}$ CFU MRSA for $1 \mathrm{~h}$ and exposed to SAAP-148, pexiganan, chlorhexidine or PBS for $1 \mathrm{~h}$. Subsequently, samples were homogenized in PBS or $0.05 \%(\mathrm{wt} / \mathrm{v})$ SPS and the number of viable bacteria was assessed.
\end{abstract}

Results: All tested antimicrobials displayed residual activity in tissue samples, resulting in a lower recovery of surviving bacteria on agar. SPS concentrations at $\geq 0.05 \%(\mathrm{wt} / \mathrm{v})$ were able to neutralize the antimicrobial activity of SAAP-148, pexiganan and chlorhexidine, but not of SSD, Bactroban and Fucidin. Finally, SPS-neutralization in in vitro and ex vivo efficacy tests of SAAP-148, pexiganan and chlorhexidine against gram-positive and gram-negative bacteria resulted in significantly higher numbers of CFU compared to control samples without SPS-neutralization.

Conclusions: SPS was successfully used to neutralize residual activity of SAAP-148, pexiganan and chlorhexidine and this prevented an overestimation of their efficacy.

Keywords: Sodium polyanethol sulfonate, Antimicrobial peptides, SAAP-148, Efficacy, Residual activity, Neutralization

\footnotetext{
* Correspondence: gdijksteel@burns.nl

${ }^{1}$ Association of Dutch Burn Centres, Zeestraat 29, 1941 AJ Beverwijk, The Netherlands

${ }^{2}$ Department of Plastic, Reconstructive \& Hand Surgery, Amsterdam

Movement Sciences, Amsterdam University Medical Centres, Free University

of Amsterdam, De Boelelaan 1117, 1081 HV Amsterdam, The Netherlands

Full list of author information is available at the end of the article
}

(c) The Author(s). 2019 Open Access This article is distributed under the terms of the Creative Commons Attribution 4.0 International License (http://creativecommons.org/licenses/by/4.0/), which permits unrestricted use, distribution, and reproduction in any medium, provided you give appropriate credit to the original author(s) and the source, provide a link to the Creative Commons license, and indicate if changes were made. The Creative Commons Public Domain Dedication waiver (http://creativecommons.org/publicdomain/zero/1.0/) applies to the data made available in this article, unless otherwise stated. 


\section{Background}

Efficacy is a fundamental parameter in the discovery and development of antimicrobial agents. To determine the efficacy of an antimicrobial treatment, the drug must be neutralized immediately after the treatment time to prevent an overestimation of efficacy [1]. Neutralization of the residual activity can be achieved by reducing the effective concentration of the antimicrobial agent via dilution, filtration, centrifugation, chemical inactivation and other methods [2,3]. However, chemical inactivation is probably the most accurate procedure as the residual antimicrobials are immediately inactivated after addition of the chemicals, also known as neutralizing agents, to the test sample. Nevertheless, chemical inactivation of antimicrobial agents is not commonplace in drug efficacy testing.

Over the past years, different neutralizing agents have been used to inactivate different antimicrobials, e.g.: $i$ ) lecithin and polysorbate 20 have been used for the neutralization of chlorhexidine [1, 4], ii) sodium thiosulphate was used for iodine [5] and iii) chondroitin sulfate for polyhexamethylene biguanide [6]. In the absence of neutralizing agents, bacteria surviving the efficacy test may be completely eradicated by residual antimicrobial activity during sample preparation and/or microbiological quantification [7]. This shows the relevance of neutralizing agents in efficacy testing of antimicrobials.

Currently, there is an increasing interest in the development of antimicrobial peptides (AMPs) because they are highly effective against antibiotic resistant bacteria $[8,9]$. AMPs eradicate bacteria by disrupting the bacterial membrane and therefore, it is believed that bacterialresistance to AMPs is less likely to occur [10, 11]. For these reasons, AMPs are considered promising therapeutic candidates for the development of agents to combat bacterial infections not effectively responding to antibiotics. We aim to accurately determine the efficacy of highly potent AMPs using neutralizing agents.

Previously, Edberg et al. reported that aminoglycoside and polymyxin antibiotics can be neutralized selectively using sodium polyanethol sulfonate (SPS) [12]. Yet, SPS is not commonly used to neutralize residual antimicrobial activity in efficacy tests. In the current study, we investigated the efficacy of various antimicrobial agents in the presence and absence of SPS with the aim to $i$ ) determine the applicability of SPS for the neutralization of different antimicrobial agents and ii) evaluate the importance of neutralization of residual antimicrobial activity in test samples.

\section{Methods}

Antimicrobial agents

SAAP-148 is a synthetic AMP inspired on the structure of the human cathelicidin, LL-37 [13]. Pexiganan is an analogue of the frog peptide called magainin 2 and was previously clinically tested [14]. Both SAAP-148 and pexiganan were synthesized, purified and identified as described by Nell et al. [15]. Lyophilized peptide was dissolved in phosphate-buffered saline (PBS) (Gibco, Paisley, UK) and aliquots of the peptide in PBS were stored at $-20^{\circ} \mathrm{C}$ until use. The other antimicrobial agents used in this study were $1 \%(\mathrm{wt} / \mathrm{wt})$ silver sulfadiazine (SSD) cream (Pharmacy of the Medical Centre Alkmaar, Alkmaar, the Netherlands), $0.5 \%(\mathrm{v} / \mathrm{v})$ chlorhexidine in $70 \%$ alcohol (Orphi Farma B.V., Lage Zwaluwe, the Netherlands), 2\% (wt/wt) mupirocin in an ointment (Bactroban; GlaxoSmithKline B.V., Zeist, the Netherlands) and $2 \%(\mathrm{wt} / \mathrm{wt}$ ) fusidic acid in an ointment (Fucidin; Leo Pharma B.V., Amsterdam, the Netherlands).

\section{Preparation of ex vivo models}

Human skin was obtained after elective surgery at the Red Cross Hospital (Beverwijk, the Netherlands) according to institutional guidelines and following "code of conduct for responsible use", drafted by Federa (Foundation Federation of Dutch Medical Scientific Societies). Human skin grafts with a thickness of $0.8 \mathrm{~mm}$ were prepared from this tissue using a dermatome (Aesculap AG \& Co. KG, Tuttlingen, Germany). Excision wounds were inflicted by removing $0.3 \mathrm{~mm}$ of the upper part of the skin containing the epidermis using a dermatome (width $7 \mathrm{~mm}$ ). Subsequently, the graft was cut into pieces of approximately $1 \mathrm{~cm}^{2}$ using a scalpel.

\section{Bacterial culture}

Methicillin-resistant Staphylococcus aureus (MRSA; clinical isolates LUH14616 [16] and Mu50, ATCC 700699), Enterococcus faecalis (ATCC 29212), Pseudomonas aeruginosa (PAO1; ATCC BAA47), Escherichia coli (ATCC 35218) and a clinical isolate of Acinetobacter baumannii were used. The clinical isolate of $A$. baumannii was kindly provided by Drs. Jan Sinnige (Regional Laboratory for Medical Microbiology and Public Health Haarlem, Haarlem, the Netherlands). Bacteria were stored in LuriaBertani (LB; Oxoid, Ltd., Basingstoke, UK) medium supplemented with $15 \%(\mathrm{v} / \mathrm{v})$ glycerol at $-80^{\circ} \mathrm{C}$. LB agar plates were used to grow the inoculae at $37^{\circ} \mathrm{C}$ and $5 \%$ $\mathrm{CO}_{2}$ overnight. To create a mid-log phase growth culture, bacteria were cultured in $\mathrm{LB}$ medium at $37^{\circ} \mathrm{C}$, shaken at $200 \mathrm{rpm}$. The bacterial culture was centrifuged at $3600 \times g$ for $5 \mathrm{~min}$ and the pellet was re-suspended in PBS to the desired bacterial concentration, based on the optical density at $600 \mathrm{~nm}$.

\section{Assessment of residual antimicrobial activity}

Ex vivo excision wound models were topically exposed to 20 or $200 \mu \mathrm{L}$ of $1 \%$ (wt/v) SAAP-148 in PBS, $1 \%$ (wt/ v) pexiganan in $\mathrm{PBS}, 1 \%(\mathrm{wt} / \mathrm{wt}) \mathrm{SSD}, 0.5 \%(\mathrm{v} / \mathrm{v})$ 
chlorhexidine in 70\% alcohol, 2\% (wt/wt) Bactroban, 2\% (wt/wt) Fucidin or PBS for $1 \mathrm{~h}$. Tissue samples were transferred to polypropylene vials containing $1 \mathrm{~mL}$ of PBS and a 7-mm metal bead. Tissue homogenates were prepared using a TissueLyser LT (Qiagen, Venlo, the Netherlands) set at $50 \mathrm{~Hz}$ for $4 \mathrm{~min}$. Subsequently, $5 \mu \mathrm{L}$ of 10 -fold serially diluted $10^{7}$ colony forming units (CFU)/mL MRSA (LUH14616) were plated on LB agar plates and $5 \mu \mathrm{L}$ of 10 -fold serially diluted homogenates of excision wound models exposed to an antimicrobial agent or PBS were pipetted on top of the bacteria. The surviving bacteria in each dilution step were evaluated after overnight incubation of the agar plates at $37^{\circ} \mathrm{C}$ and $5 \% \mathrm{CO}_{2}$.

\section{SPS-neutralization of antimicrobial activity}

Ten $\mu \mathrm{L}$ of PBS or one of the antimicrobial agents: $1 \%$ $(\mathrm{wt} / \mathrm{v})$ SAAP-148 in PBS, $1 \%(\mathrm{wt} / \mathrm{v})$ pexiganan in PBS, $1 \%$ (wt/wt) SSD, 0.5\% (v/v) chlorhexidine in 70\% alcohol, $2 \%$ (wt $/ \mathrm{wt}$ ) Bactroban or $2 \%$ (wt $/ \mathrm{wt}$ ) Fucidin were added to polypropylene vials containing $400 \mu \mathrm{L}$ of PBS, 0.05 , $0.1,0.5 \%$ or $1 \%$ (wt/v; final concentrations) SPS (Fig. 1) in PBS (Merck, KGaA, Darmstadt, Germany). Subsequently, $90 \mu \mathrm{L}$ of $5.6 \times 10^{5} \mathrm{CFU} / \mathrm{mL}$ MRSA (LUH14616) suspension were added to the vials and the mixtures were briefly vortexed. After $30 \mathrm{~min}$ incubation at $37^{\circ} \mathrm{C}$ and $5 \% \mathrm{CO}_{2}$, a $7 \mathrm{~mm}$ metal bead was added to the vials to homogenize the samples using a TissueLyser set at $50 \mathrm{~Hz}$ for $4 \mathrm{~min}$. This was performed to mimic the procedure of the skin samples. Ten-fold serial dilutions of the homogenates were cultured on LB agar plates to

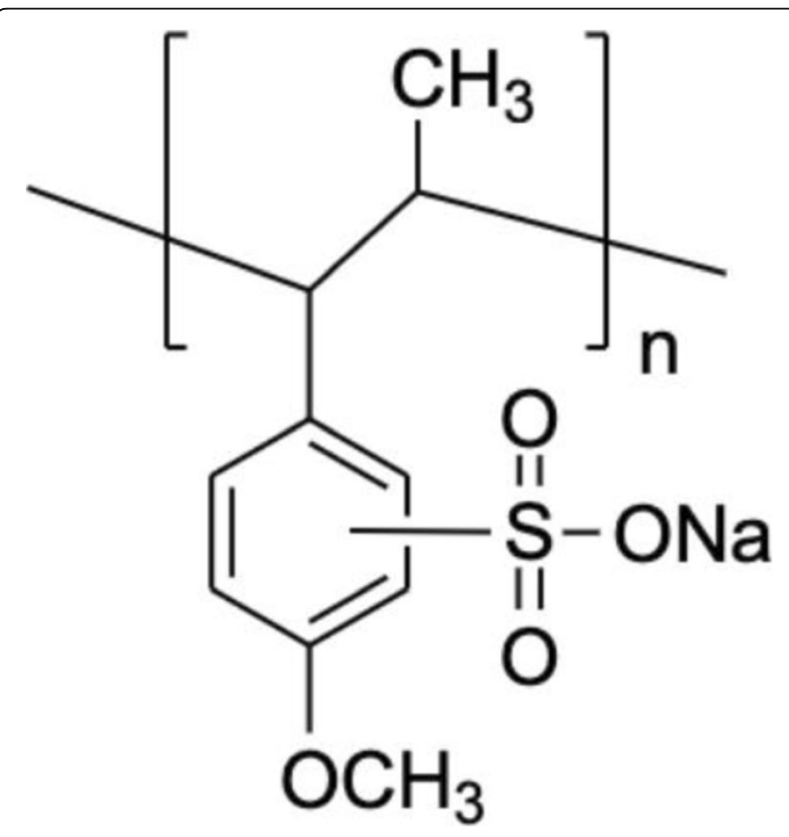

Fig. 1 Structural formula of SPS (ChemDraw, PerkinElmer, 2018) quantify the number of surviving bacteria after overnight incubation at $37^{\circ} \mathrm{C}$ and $5 \% \mathrm{CO}_{2}$.

\section{Efficacy testing in the absence and presence of neutralizing agent SPS}

In vitro: Mixtures of $10 \mu \mathrm{L}$ of $1 \%(\mathrm{wt} / \mathrm{v})$ SAAP-148 in PBS or PBS and $90 \mu \mathrm{L}$ of $10^{7} \mathrm{CFU} / \mathrm{mL}$ MRSA (LUH14616 and Mu50), E. faecalis (ATCC 29212), P. aeruginosa (PAO1; ATCC BAA47), E. coli (ATCC 35218 ) or A. baumannii were incubated for $30 \mathrm{~min}$ at $37^{\circ} \mathrm{C}$ and $5 \% \mathrm{CO}_{2}$. Subsequently, $400 \mu \mathrm{L}$ of PBS with or without $0.05 \%(\mathrm{wt} / \mathrm{v})$ SPS and a $7-\mathrm{mm}$ metal bead were added to the mixtures to prepare homogeneous suspensions using a TissueLyser set at $50 \mathrm{~Hz}$ for $4 \mathrm{~min}$.

Ex vivo: Excision wound models were inoculated with $10 \mu \mathrm{L}$ of $10^{7} \mathrm{CFU} / \mathrm{mL}$ MRSA (LUH14616) for $1 \mathrm{~h}$ and then topically exposed to $20 \mu \mathrm{L}$ of $1 \%$ (wt/v) SAAP-148 in PBS, $1 \%(\mathrm{wt} / \mathrm{v})$ pexiganan in PBS, $0.5 \%(\mathrm{v} / \mathrm{v})$ chlorhexidine in $70 \%$ alcohol or PBS for $1 \mathrm{~h}$. Thereafter, tissue samples were transferred to polypropylene vials containing a $7-\mathrm{mm}$ metal bead and $1 \mathrm{~mL}$ of PBS with or without $0.05 \%(\mathrm{wt} / \mathrm{v})$ SPS to prepare tissue homogenates using a TissueLyser set at $50 \mathrm{~Hz}$ for $4 \mathrm{~min}$.

To determine the number of viable bacteria, 10 -fold serial dilutions of the homogenates were cultured overnight at $37^{\circ} \mathrm{C}$ and $5 \% \mathrm{CO}_{2}$ on LB agar plates.

\section{Statistical analysis}

To determine the statistically significant differences between two sample groups, the non-parametric Kruskal-Wallis test and the Mann Whitney rank-sum test were used.

\section{Results}

Residual antimicrobial activity in tissue samples

To evaluate the presence of residual antimicrobial activity, ex vivo excision wound models were topically exposed to $20 \mu \mathrm{L}$ of various antimicrobial agents or PBS for $1 \mathrm{~h}$, and homogenates were prepared. Subsequently, serial dilutions of these homogenates were pipetted on top of serially diluted MRSA (LUH14616) suspensions on agar. All tested antimicrobial agents showed residual activity (Fig. 2). Particularly for the undiluted SSD-, chlorhexidine-, Bactroban- and Fucidin-exposed tissue homogenates bacterial killing was evident as inhibition zones appeared or bacteria were completely eradicated. Only at 1000 -fold dilution of the Bactroban- and Fucidin-exposed tissue homogenates, surviving bacteria were detected. In contrast, the surviving bacteria of the SAAP-148- and pexiganan-exposed tissue homogenates were comparable to that of the PBS-exposed tissue homogenates. However, when 10-fold higher antimicrobial amounts $(200 \mu \mathrm{L})$ were used for the SAAP-148- and pexiganan-exposed tissue homogenates, bacterial killing was observed. Inhibition zones appeared for the undiluted pexiganan-exposed 


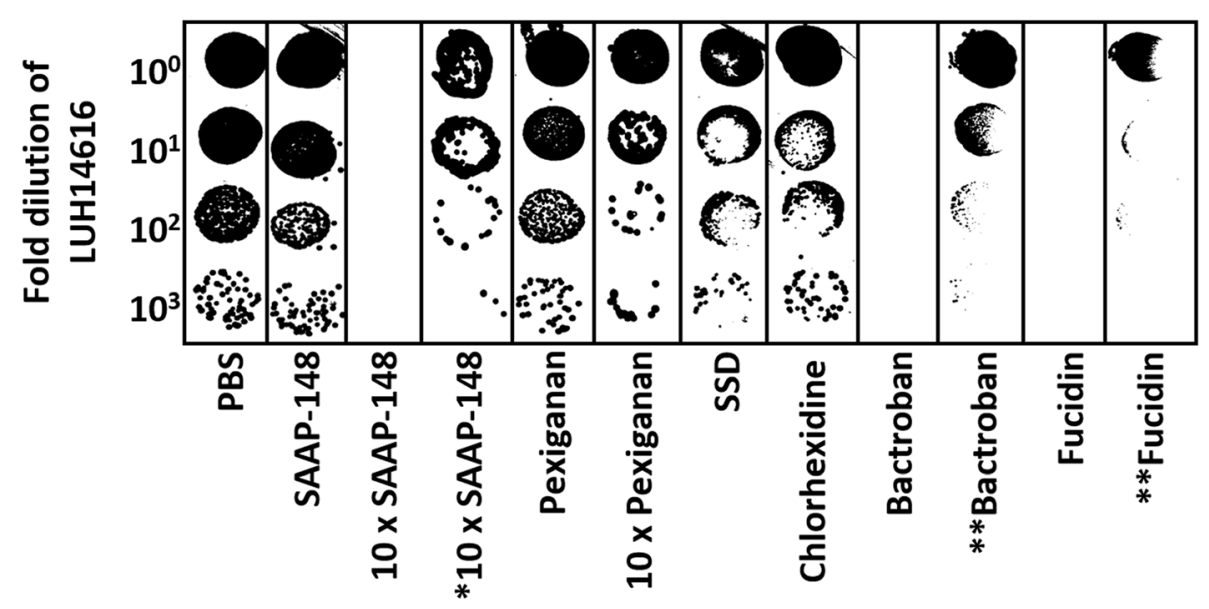

\section{$* 10^{1} \times$ diluted \\ $* * 10^{3} \mathrm{x}$ diluted}

Fig. 2 Residual antimicrobial activity. Five $\mu \mathrm{L}$ of serially diluted LUH14616 were plated on agar and $5 \mu \mathrm{L}$ of homogenates of excision wound models exposed to $20 \mu \mathrm{L}$ or 10 -fold higher amounts $(200 \mu \mathrm{L})$ of various antimicrobial agents or PBS were pipetted on top of the bacteria. Results of one experiment are illustrated as the surviving bacteria in each dilution step

tissue homogenate whereas for the undiluted SAAP-148exposed tissue homogenate bacteria were completely eradicated. Interestingly, at 10-fold dilution of this SAAP148-exposed tissue homogenate inhibition zones appeared (Fig. 2), indicating that at high antimicrobial concentrations residual activity is highly effective against bacteria.

\section{Neutralization of antimicrobial activity by SPS}

To determine whether SPS (Fig. 1) can effectively neutralize different antimicrobial agents, mixtures containing $400 \mu \mathrm{L}$ of PBS or $0.05,0.1,0.5 \%$ or $1 \%$ (wt $/ \mathrm{v}$ ) SPS in PBS and $10 \mu \mathrm{L}$ of various antimicrobial agents or PBS were prepared. Subsequently, MRSA (LUH14616) with a final concentration of $10^{5} \mathrm{CFU} / \mathrm{mL}$ was added to these mixtures to determine the antimicrobial effect. Of note, the increasing concentrations of SPS did not affect the bacterial survival as the number of viable bacteria in the presence of SPS was comparable to the number of viable bacteria in PBS alone (Fig. 3). The antimicrobial activity of SAAP-148 $(200 \mu \mathrm{g} / \mathrm{mL})$, pexiganan $(200 \mu \mathrm{g} / \mathrm{mL})$ and chlorhexidine $(100 \mu \mathrm{g} / \mathrm{mL})$ was efficiently

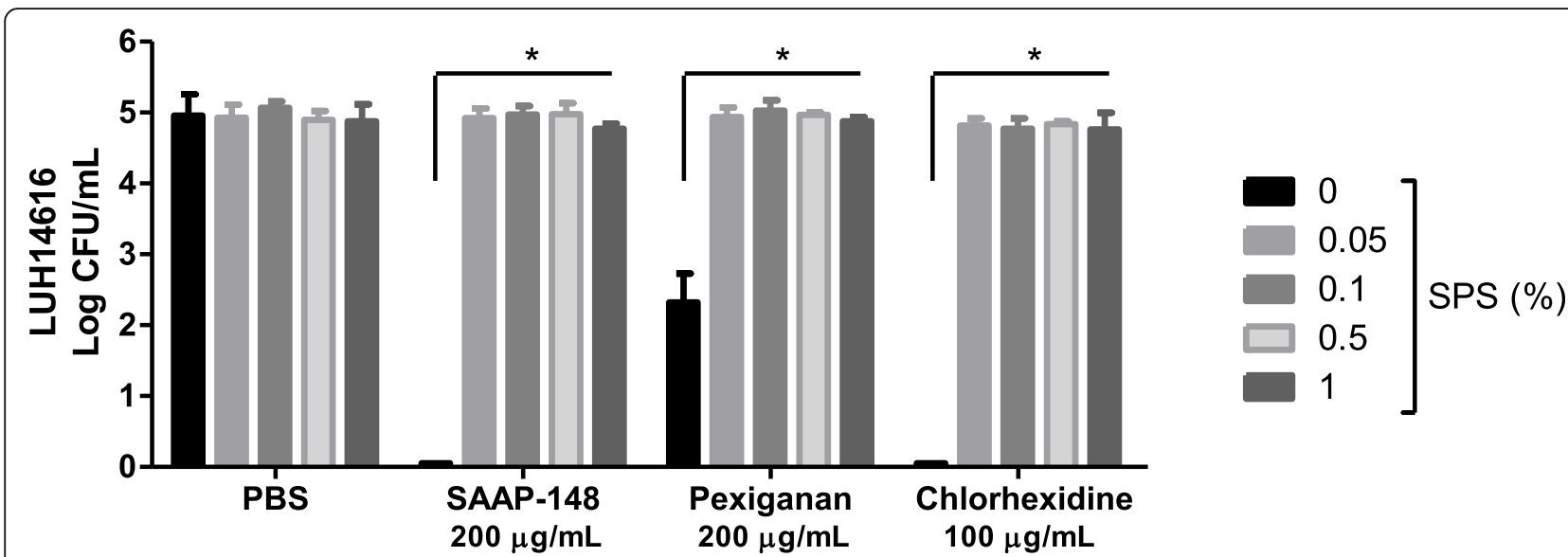

Fig. 3 Effect of SPS on the antimicrobial activity of various antimicrobial agents. Mixtures of $10 \mu \mathrm{L}$ of SAAP-148 (1\% wt/v), pexiganan (1\% wt/v), chlorhexidine $(0.5 \% \mathrm{v} / \mathrm{v}$ in $70 \%$ alcohol) or PBS and $400 \mu \mathrm{L}$ of PBS, $0.05,0.1,0.5 \%$ or $1 \%$ (wt/v; final concentrations) SPS in PBS were prepared. Ninety $\mu \mathrm{L}$ of LUH14616 with a final concentration of $10^{5} \mathrm{CFU} / \mathrm{mL}$ were added to these mixtures to determine the antimicrobial activity after 30 min incubation at $37^{\circ} \mathrm{C}$ and $5 \% \mathrm{CO}_{2}$. The means and standard deviations (SD) of three independent experiments performed in duplicate are shown. Results are expressed as the number of surviving bacteria in log $10 \mathrm{CFU} / \mathrm{mL}$. * indicates significant difference as compared to the samples without SPS (* $p<0.05)$ 
neutralized by $\geq 0.05 \%$ (wt/v) SPS, resulting in the complete survival of approximately $10^{5} \mathrm{CFU} / \mathrm{mL}$ MRSA (LUH14616) (Fig. 3). However, the antimicrobial activity of SSD, Bactroban, and Fucidin was not affected by these SPS concentrations as either no colonies were detected or colonies were found in 10-or more fold dilutions but not in the undiluted samples on agar (data not shown).

\section{Efficacy testing of antimicrobial agents in the absence or} presence of SPS

To test the effect of $0.05 \%(w t / v)$ SPS in PBS on the efficacy of SAAP-148 against gram-positive and gramnegative bacteria, $10 \mu \mathrm{L}$ of $1 \%$ (wt/v) SAAP-148 in PBS or PBS was mixed with $90 \mu \mathrm{L}$ of MRSA (LUH14616 and Mu50), E. faecalis (ATCC 29212), P. aeruginosa (PAO1; ATCC BAA47), E. coli (ATCC 35218) or a clinical isolate of $A$. baumannii for $30 \mathrm{~min}$. Subsequently, the samples were homogenized in PBS with or without $0.05 \%(\mathrm{wt} / \mathrm{v})$ SPS and the number of viable bacteria was determined. Of note, SPS did not affect the bacterial survival of these types of bacteria as the number of viable bacteria in the presence of SPS was comparable to the number of viable bacteria in PBS alone (Fig. 4). More interestingly, SPSneutralization of SAAP-148 resulted in approximately $100 \mathrm{CFU} / \mathrm{mL}$ of surviving bacteria, whereas without SPSneutralization, all bacteria were eradicated except for $E$. faecalis in two of six experiments (average $10 \mathrm{CFU} / \mathrm{mL}$ ). The same was found for SAAP-148 $(p<0.001)$, pexiganan $(p<0.05)$ and chlorhexidine $(p<0.01)$ in ex vivo excision wound models that had been inoculated with $10^{5} \mathrm{CFU}$ MRSA (LUH14616) (Fig. 5).

\section{Discussion}

We have shown that all tested antimicrobial agents displayed residual activity in tissue homogenates, as inhibition zones appeared on the agar or the number of CFU decreased. Notably, when $20 \mu \mathrm{L}$ of SAAP-148 $(200 \mu \mathrm{g} /$ $\mathrm{mL}$ ) were used for the SAAP-148-exposed tissue homogenates residual activity was not evident; however, when 10 -fold higher antimicrobial amounts $(200 \mu \mathrm{L} ; 2 \mathrm{mg} / \mathrm{mL})$ were used for the SAAP-148-exposed tissue homogenates, inhibition zones appeared when this homogenate was 10-times diluted $(200 \mu \mathrm{g} / \mathrm{mL})$ (Fig. 2). This suggests that SAAP-148 interacts with tissue components and that the remaining amounts of active antimicrobials were higher and thus more effective against bacteria when 10-fold higher antimicrobial amounts were used to prepare the homogenate.

As recommended in the American Society for Testing and Materials standard, we did not only determine the efficacy of the polyanionic detergent SPS (Fig. 1) in inactivating various antimicrobial agents but also determined its toxicity for the bacteria used in this study [17]. We anticipated that SPS would not neutralize the activity of SSD, Bactroban and Fucidin, due to their net negative charge at physiological conditions, which prevents the binding of SPS via electrostatic attraction. Nevertheless, SPS not only effectively neutralizes aminoglycoside and polymyxin antibiotics but also other antimicrobials, including SAAP-148,

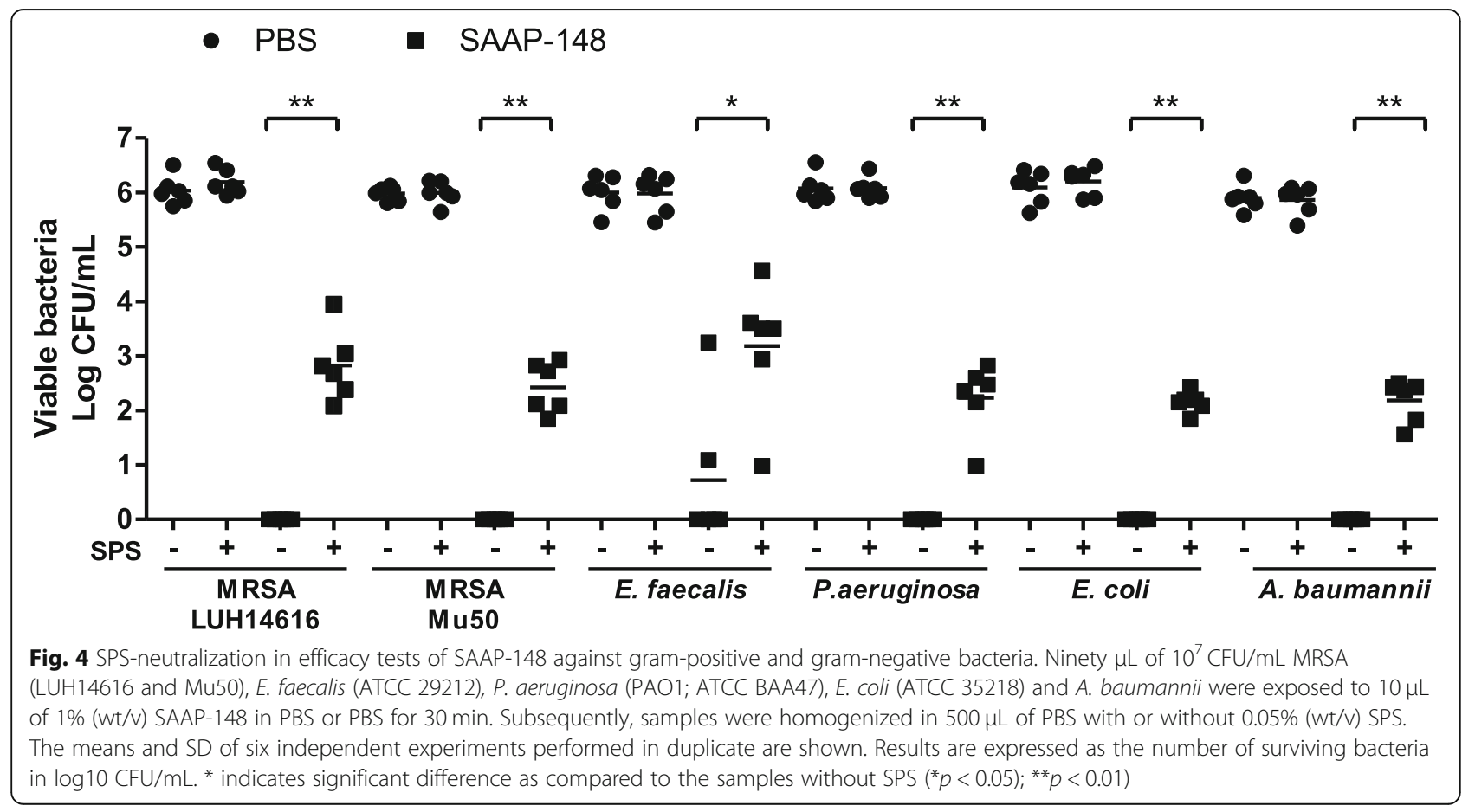




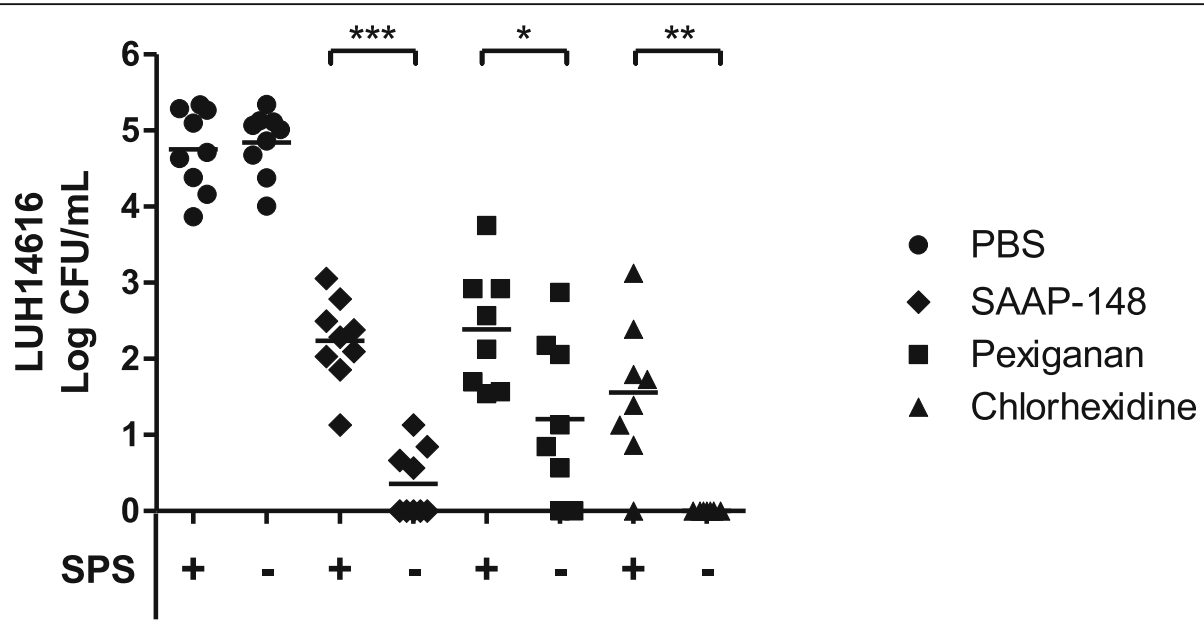

Fig. 5 SPS-neutralization of residual activity of various antimicrobial agents. Excision wound models were inoculated with $10^{5} \mathrm{CFU} / \mathrm{mL} \mathrm{LUH} 14616$ for $1 \mathrm{~h}$ and exposed to $20 \mathrm{\mu L}$ of SAAP-148 (1\% wt/v), pexiganan ( $1 \% \mathrm{wt} / \mathrm{v})$, chlorhexidine $(0.5 \% \mathrm{v} / \mathrm{v}$ in $70 \%$ alcohol) or PBS for $1 \mathrm{~h}$. Subsequently, the models were homogenized in $1 \mathrm{~mL}$ of PBS with or without $0.05 \%(\mathrm{wt} / \mathrm{v})$ SPS. The means and SD of at least eight independent experiments performed in triplicate are shown. Results are expressed as the number of surviving bacteria in log $10 \mathrm{CFU} / \mathrm{mL} .{ }^{*}$ indicates significant difference as compared to the samples without SPS $\left.\left({ }^{*} p<0.05\right) ;{ }^{* *} p<0.01 ;{ }^{* *} p<0.001\right)$

pexiganan and chlorhexidine (Fig. 3). Because SPS binds to and therefore inactivates antimicrobials depending on their cationic strength, it is believed that SPS could be more commonly used for the neutralization of AMPs in efficacy tests as they are usually highly positively charged.

Furthermore, the effect of residual activity of SSD, Bactroban and Fucidin on bacteria could be inhibited via dilution as colonies could be observed in 10-or more fold dilutions but not in the undiluted samples. However, for highly potent antimicrobials dilution of test samples may not be effective enough to eliminate the residual activity. To effectively and efficiently neutralize residual activity of antimicrobials alternatives to dilution are required. Already in 1993, Zabinski et al. reported on the use of beads that can neutralize residual activity of quinolone antibiotics [18]. We studied SPS-neutralization in efficacy tests of SAAP148 against gram-positive and gram-negative bacteria and for different antimicrobial agents such as pexiganan and chlorhexidine. SPS-neutralization of these antimicrobials was required to prevent ongoing bacterial killing during sample preparation (Figs. 4 and 5). This is in agreement with Kampf et al., who reported that neutralizing agents were required to effectively inactivate a chlorhexidinecontaining hand rub in efficacy tests $[1,4]$. Thus, accurate neutralization of residual antimicrobial activity in efficacy tests can prevent an overestimation of the drug's efficacy.

Previously, MacDonald et al. reported a minimal inhibitory concentration of $\leq 16 \mu \mathrm{g} / \mathrm{mL}$ for pexiganan against bacteria isolated from infected diabetic foot ulcers. This in vitro efficacy of pexiganan was not superior but equivalent to the conventional antibiotic ofloxacin [19]. A higher dosage of $2 \%(20,000 \mu \mathrm{g} / \mathrm{mL})$ pexiganan would be more favorable in the clinical studies for the treatment of infected diabetic foot ulcers. However, pexiganan failed to demonstrate its superiority over ofloxacin with statistically significant data in the phase III clinical trials [14]. As no neutralizing agents were used in these studies, the efficacy of pexiganan might be overestimated, especially because a high antimicrobial dosage was used in vivo. In line with this suggestion, we emphasize the importance of neutralization of residual antimicrobial activity in efficacy testing of novel AMPs, such as SAAP-148.

\section{Conclusions}

Depending on the antimicrobial agent and the concentration used, residual activity in tissue samples can be high. Residual activity of different antimicrobial agents, including SAAP-148, pexiganan and chlorhexidine, can be neutralized using SPS. As a consequence, an overestimation of the drug's efficacy is prevented. Thus, accurate preclinical efficacy testing of novel AMPs, using SPSneutralization, will allow appropriate designs for clinical testing, if relevant.

\section{Abbreviations}

AMP: Antimicrobial peptide; CFU: Colony forming units; LB: Luria-Bertani; MRSA: Methicillin-resistant Staphylococcus aureus; PBS: Phosphate-buffered saline; SD: Standard deviations; SPS: Sodium polyanethol sulfonate; SSD: Silver sulfadiazine

\section{Acknowledgments}

We thank Dr. Bas Zaat of the Department of Medical Microbiology at the Academic Medical Centre Amsterdam in the Netherlands, for recommending SPS as a neutralizer for SAAP-148. We also thank the clinical microbiologist Drs. Jan Sinnige (Regional Laboratory for Medical Microbiology and Public Health Haarlem in the Netherlands) for providing us with E. faecalis (ATCC 29212), E. coli (ATCC 35218) and a clinical isolate of A. baumannii. and Dr. Willem van Wamel (Department of Medical Microbiology and Infectious 
Diseases of the Erasmus MC Rotterdam) for providing us with MRSA Mu50 (ATCC 700699).

\section{Authors' contributions}

PHN supplied the AMPs SAAP-148 and pexiganan. GSD performed the experiments and wrote a draft version of the manuscript. MMWU, EM and BKHLB contributed to the design of the study. PHN and BKHLB substantively revised the manuscript. All authors assisted with the interpretation of the data and agreed to be personally accountable for the accuracy and integrity of this work. All authors read and approved the final manuscript.

\section{Funding}

The collaboration project was funded by the Ministry of Economic Affairs through the public-private partnership (PPP) allowance made available by Health-Holland, Top Sector life Sciences \& Health as well as by a contribution from the Dutch Burns Foundation, Madam Therapeutics B.V., Mölnlycke Health Care AB, Leiden University Medical Centre, Amsterdam University Medical Centre and the Association of Dutch Burn Centres [LSH-TKI4043100-98-017]. The funding body did not play a role in the design of the study and collection, analysis, and interpretation of data and in writing the manuscript.

\section{Availability of data and materials}

The datasets used and analyzed during the current study are available from the corresponding author on reasonable request.

\section{Ethics approval and consent to participate}

Human skin was obtained according to institutional guidelines and medical research "code of conduct for responsible use", drafted by Federa (Foundation Federation of Dutch Medical Scientific Societies).

\section{Consent for publication}

Not applicable.

\section{Competing interests}

The authors declare that they have no competing interests.

\section{Author details}

'Association of Dutch Burn Centres, Zeestraat 29, 1941 AJ Beverwijk, The Netherlands. ${ }^{2}$ Department of Plastic, Reconstructive \& Hand Surgery, Amsterdam Movement Sciences, Amsterdam University Medical Centres, Free University of Amsterdam, De Boelelaan 1117, 1081 HV Amsterdam, The Netherlands. ${ }^{3}$ Department of Infectious Diseases, Leiden University Medical Centre, Albinusdreef 2, 2333 ZA Leiden, The Netherlands.

Received: 19 July 2019 Accepted: 11 December 2019

Published online: 30 December 2019

\section{References}

1. Kampf G, Shaffer M, Hunte C. Insufficient neutralization in testing a chlorhexidine-containing ethanol-based hand rub can result in a false positive efficacy assessment. BMC Infect Dis. 2005:5:1-5.

2. Eissa ME, Nouby AS. Validation of spore-forming organisms recovery from peroxygen-based disinfectants. J Pharm Res Clin Pract 2014:4:23-32.

3. Sutton SW, Proud DW, Rachui S, Brannan DK. Validation of microbial recovery from disinfectants. PDA J Pharm Sci Technol. 2002;56:255-66.

4. Reichel M, Heisig P, Kampf G. Pitfalls in efficacy testing - how important is the validation of neutralization of chlorhexidine digluconate? Ann Clin Microbiol Antimicrob. 2008;7:1-7.

5. Phillips PL, Yang Q, Davis S, Sampson EM, Azeke Jl, Hamad A, et al. Antimicrobial dressing efficacy against mature Pseudomonas aeruginosa biofilm on porcine skin explants. Int Wound J. 2015;12:469-83.

6. Müller $\mathrm{G}$, Kramer A. In vitro action of a combination of selected antimicrobial agents and chondroitin sulfate. Chem Biol Interact. 2000;124: 77-85.

7. Werner HP, Engelhardt C. Problematik der inaktivierung am beispiel des in vitro-tests. Hyg Med. 1978;3:326-30

8. Park S-C, Park Y, Hahm K-S. The role of antimicrobial peptides in preventing multidrug-resistant bacterial infections and biofilm formation. Int J Mol Sci. 2011;12:5971-92
9. Diamond G, Beckloff N, Weinberg A, Kisich KO. The roles of antimicrobial peptides in innate host defense. Curr Pharm Des. 2009;15:2377-92.

10. Bechinger B, Gorr S-U. Antimicrobial peptides: mechanisms of action and resistance. J Dent Res. 2017:96:254-60.

11. Zasloff M. Antimicrobial peptides of multicellular organisms. Nature. 2002; 415:389-95.

12. Edberg SC, Bottenbley CJ, Gam K. Use of sodium polyanethol sulfonate to selectively inhibit aminoglycoside and polymyxin antibiotics in a rapid blood level antibiotic assay. Antimicrob Agents Chemother. 1976;9:414-7.

13. de Breij A, Riool M, Cordfunke RA, Malanovic N, de Boer L, Koning Rl, et al. The antimicrobial peptide SAAP-148 combats drug-resistant bacteria and biofilms. Sci Transl Med. 2018;10(423):eaan4044.

14. Lipsky BA, Holroyd KJ, Zasloff M. Topical versus systemic antimicrobial therapy for treating mildly infected diabetic foot ulcers: a randomized, controlled, double-blinded, multicenter trial of pexiganan cream. Clin Infect Dis. 2008;47:1537-45.

15. Nell MJ, Tjabringa GS, Wafelman AR, Verrijk R, Hiemstra PS, Drijfhout JW, et al. Development of novel LL-37 derived antimicrobial peptides with LPS and LTA neutralizing and antimicrobial activities for therapeutic application. Peptides. 2006:27:649-60.

16. Haisma EM, de Breij A, Chan H, van Dissel JT, Drijfhout JW, Hiemstra PS, et al. LL-37-derived peptides eradicate multidrug-resistant Staphylococcus aureus from thermally wounded human skin equivalents. Antimicrob Agents Chemother. 2014;58:4411-9.

17. Anonymous. ASTM E1054 : standard test methods for evaluation of inactivators of antimicrobial agents. ASTM International. 2002. https://global. ihs.com/doc_detail.cfm?document_name=ASTM E1054\&item_s_key=0001 9439. Accessed 26 Apr 2019.

18. Zabinski RA, Larsson AJ, Walker KJ, Gilliland SS, Rotschafer JC. Elimination of quinolone antibiotic carryover through use of antibiotic-removal beads. Antimicrob Agents Chemother. 1993;37:1377-9.

19. Ge Y, MacDonald D, Henry MM, Hait HI, Nelson KA, Lipsky BA, et al. In vitro susceptibility to pexiganan of bacteria isolated from infected diabetic foot ulcers. Diagn Microbiol Infect Dis. 1999;35:45-53.

\section{Publisher's Note}

Springer Nature remains neutral with regard to jurisdictional claims in published maps and institutional affiliations.

\section{Ready to submit your research? Choose BMC and benefit from:}

- fast, convenient online submission

- thorough peer review by experienced researchers in your field

- rapid publication on acceptance

- support for research data, including large and complex data types

- gold Open Access which fosters wider collaboration and increased citations

- maximum visibility for your research: over $100 \mathrm{M}$ website views per year

At $\mathrm{BMC}$, research is always in progress.

Learn more biomedcentral.com/submissions 